\title{
Inequalities in stunting among under-five children in Tanzania: Decomposing the Concentration Indexes using Demographic Health Surveys from 2004/5 to $2015 / 6$
}

Edwin Musheiguza ( $\square$ musheiguzae@gmail.com )

Kilimanjaro Christian Medical University College https://orcid.org/0000-0002-7155-7346

Michael Johnson Mahande

Kilimanjaro Christian Medical University College

Elias Malamala

College of Business Education

Sia E Msuya

Kilimanjaro Christian Medical University College

Festo Charles

Ifakara Health Institute

Rune Philemon

Kilimanjaro Christian Medical University College

Melina Mgongo

Kilimanjaro Christian Medical University College

Research article

Keywords: trend, stunting, inequality, decomposition, Tanzania

Posted Date: July 29th, 2020

DOl: https://doi.org/10.21203/rs.3.rs-24183/v2

License: @ (1) This work is licensed under a Creative Commons Attribution 4.0 International License. Read Full License

Version of Record: A version of this preprint was published at International Journal for Equity in Health on January 23rd, 2021. See the published version at https://doi.org/10.1186/s12939-021-01389-3. 


\section{Abstract}

Background Child stunting is a global health concern. It has consequences on child survival, growth, and development. The absolute level of stunting has been decreasing in Tanzania although the prevalence is still high (34\%), varying across socioeconomic determinants with a larger burden among the disadvantaged group. The reduction of inequalities in stunting is very crucial as we aim to reduce stunting to $28 \%$ by 2021 . Objectives This study aimed to determine the trend, contributing factors and changes of inequalities in stunting among children aged 3 - 59 months from 2004 to 2016 Methodology Data were drawn from the Tanzania Demographic and Health Surveys. The dependent variable was stunting. The concentration index was used to quantify the magnitude of inequalities in stunting for each year. To get the contribution of each determinant on the inequality in stunting, the concentration index was decomposed by using the Wagstaff and Watanabe decomposition methods of the concentration index. Results Inequalities in stunting insignificantly declined from -0.019 ( $p<0.001)$ in 2004 to $-0.018(p<0.001)$ in 2010 and then to $-0.0096(p<0.001)$. Disparities in the distribution of wealth index (mean contribution $>84.7 \%$ ) and maternal years of schooling (mean contribution > 22.4\%) increased the levels of inequalities in stunting in all survey years. Ruralurban differences reduced inequalities in stunting although its contribution changed over time. Conclusion Inequalities in stunting declined, differentials in wealth index and maternal education had increased contribution to the levels of inequalities. To significantly reduce the larder burden of stunting among the disadvantaged groups, initiatives should be embarked on the distribution of social services like water, health infrastructures, and education.

\section{Background}

Stunting is a global health problem that resulted from poor diet intake and recurrent infections (1). Stunting leads to loss of physical growth potential, cognitive impairments, and increased risk of chronic diseases such as obesity, diabetes, and cerebral pulse (2,3) as well as morbidity and mortality (3). Furthermore, stunting leads to a 2- 3 reduce years of school attendance, lower reading capacity, and 22\% lower income in adulthood (4). Uneven distribution of stunting across socioeconomic determinants is termed as socioeconomic inequalities in stunting (5). Socioeconomic inequalities in stunting are unjust as they result from the unfair distribution of resources, have spillover effects, and hence increases income inequalities (6). They impact social gradient in health (7) and decelerated the achievement of Millennium Development Goals (MDGs) by 2015 (6).

Globally, stunting declined from 39.7 million (41.1\%) in 1990 to 155 million children in 2017 (1,3). The prevalence of stunting varied across countries ranging from $2 \%$ in high-income countries to more than $50 \%$ in low-income countries (8). Children living in the poorest wealth index had increased odds of 1.2 to 1.7 folds in 2000 and 2014 respectively compared to a child living in the richest wealth index households (1). Stunting decline in other continents although a steady increase from 50.6 million in 2000 to 58.7 million in 2017 in Africa was observed (1). In Tanzania, stunting declined from $50 \%$ in $1991 / 92$ to $34 \%$ in 2016 ; varying across socioeconomic determinants (9). In 2015 ; about $39.9 \%$ and $19.2 \%$ lived in poor and rich wealth index; $37.8 \%$ and $24.7 \%$ lived in rural and urban areas while $39.3 \%$ and $26.1 \%$ were born to uneducated and secondary/higher educated mothers. Stunting raged from $15 \%$ in Dar es Salaam to $56 \%$ in Rukwa (9). Studies done in Tanzania revealed that stunting is associated with socioeconomic and environmental factors (4,10-14), little is known basing on the magnitude and contributing factors of the evolvement of socioeconomic inequalities in stunting over time.

Studies in developed and developing countries documented an increasing trend of socioeconomic inequalities in stunting. Reported that socioeconomic inequalities were concentrated among the poor, mainly determined by disparities in household wealth index as well as maternal education (15,16). The difference between our studies to others is that they included children aged below three months when computing and decomposing the concentration index. Because stunting takes time, the ongoing debate among clinicians is that there might be a problem in evaluating a newborn baby if is whether stunted or not. Children aged below 3 months were excluded to minimize misclassification bias as most of the stunting starts at three months (16).

Different interventions to curb down stunting have been in place. The emphasis on exclusive breastfeeding for six months; continued breastfeeding, appropriate complementary feeding, provision of vitamin A supplementation, and deworming have been in place. Furthermore, the local production of nutritious food, provision of extra nutrients, and fortified foods access to clean and adequate water and sanitation $(9,17,18)$. The nutrition-sensitive interventions and programmes in agriculture, social safety nets, early child development, and education (19) are vital towards the alleviation of malnutrition. Collective sectoral nutrition-sensitive approaches including women's empowerment, agriculture, food systems, education, employment, social protection, and safety nets (20) are important in addressing child malnutrition.

Despite intervention in place, Tanzania observed a $0.8 \%$ annual reduction over 25 years. With this trend, is very unlikely to reach $28 \%$ by 2021 under Sustainable Development Goal (SDG) 2.2.1 and reduce inequalities in stunting thereby reaching zero stunting by 2030 under SDG 2.2. While one in three children was stunted in 2015, larger disparities in stunting across socioeconomic determinants persisted. This call upon the formulation of equity-based interventions which required evidence-based information. Therefore, this study aimed to determine the trend, contributing factors, and changes of socioeconomic inequalities in stunting among children aged 3 - 59 months from 2004/5 to 2015/6. Designing equity-based focused interventions might be a stepping stone in eradicating the observed socioeconomic inequalities in stunting and hence meet SDGs by 2030 thereby strengthening our national economy.

\section{Methods Study data and design}

We analyzed the Tanzania Demographic Health Surveys (TDHS) data using the most three recent surveys 2004, 2010, and 2016. The methodology behind data collection of TDHS data has been described elsewhere $(9,15,18)$. The current study excluded children aged below three months and those who had missing Height for Age Z- scores (HAZ). Children who were living with their mothers were included in this study, this is because the survey year 2004 didn't collect information on children not living with their mothers. Furthermore, because most of the stunting starts at 3 months (16), our study involved children

Page 2/11 
aged 3 - 59 months. We included 7053, 6782, and 9215 children with complete information for survey years 2004, 2010, and 2016 respectively. The response rate was 6897 (98\%), 6535 (96\%), and 8258 (90\%) for survey years 2004, 2010, and 2016 respectively. Data were accessed with the authorization of Demographic and Health Surveys (DHS). Because datasets contained different information, we merged the women, household member recode datasets using unique identifiers. The HAZ score file for the survey year 2004 was independent of the child dataset hence further merging was done.

\section{Outcome and explanatory variables}

The outcome variable was modeled in two different ways. Firstly, we used stunting as a binary variable (yes, no) when modeling the factors for stunting. Secondly, we used HAZ scores in their continuous form to model the factors for socioeconomic inequalities in stunting. Explanatory variables were grouped into four different categories including socio-demographic characteristics (age sex, area of residence, the zone of residence, occupation, level of education), economic characteristics (household wealth index and land ownership for agricultural activities), maternal characteristics (early initiation of breastfeeding (breastfeeding was initiated within one hour after birth), use of Antenatal care (ANC), place of delivery, type of ANC and delivery attendant), Body Mass Index (BMI) for BMI (<18.5 being underweight and $\geq 18.5$ "not underweight") and child characteristics (diarrhea status, age, sex) (3,11,13,21-24). The variables safe water and sanitation were not used as independent explanatory variables because are used in the construction of the wealth index (17).

The selection of explanatory variables to model socioeconomic inequalities in stunting was based on different literature (22,23,25-27). Variables were treated basing on $(28,29)$ recommendations. Wealth index factor scores were used instead of wealth index, and the mother's years of schooling were used instead of the mother's level of education.

\section{A proxy measure of socioeconomic status}

There are two proxy measures of socioeconomic status, household consumption and wealth asset index (28). Because DHS does not collect information on household consumption levels, we used the wealth index. The wealth index is a composite measure constructed by the principal component analysis method, a detailed explanation of the computation may be found on $(15,17,28)$.

\section{Measurement of inequalities in stunting}

We used the concentration index $(\mathrm{CIX})(28,30)$ to quantify the unequal distribution of stunting across the wealth asset index. The concentration index is defined regarding the concentration curve as twice the area between the concentration curve and the line of equality. The concentration curve plots the cumulative percentage of the health variable (y-axis) against the cumulative percentage of the population, ranked by living standards, beginning with the poorest, and ending with the richest (x-axis) (28).

$\mathrm{CIX}$ was defined by the formula (equation 1 below) where $\mu$ means the mean HAZ among children is aged $3-59$ months, $h$ is the HAZ for each observation and $r$ is the rank of the household socioeconomic status. The CIX takes values between -1 and +1 ; the value is negative when the burden of stunting lies among the poor, positive when the burden lies among the rich and zero when there is an equal prevalence of stunting across all socioeconomic groups (2830).

\section{Decomposition of inequalities in stunting}

The concentration indexes obtained for survey years 2004/5, 2010, and 2015/6 were decomposed to get the contribution of each determinant on the computed CIX. This decomposition was undertaken concerning linear regression models which links the continuous outcome variable with a set of determinants (equation 2). For $\beta_{k}$ being the coefficient of $x_{k}, \varepsilon$ being the error term (residual) while $y$ is the dependent variable (HAZ) and $\alpha$ is the constant term when all predictors equal to zero. Transforming equation 2 to the CIX of stunting, the equation of decomposing the CIX may be written as in equation 3 . For $\mu$ being the mean of $y, \bar{x}_{k}$ is the mean of $x_{k}, C I X_{k}$ is the concentration index for $x_{k}$ (the kth determinant) and $G C_{\epsilon}$ being the generalized concentration for error term $(\varepsilon)$. The element $\left(\beta_{k} \bar{x}_{k} / \mu\right)$ is an explained component while $G C_{\epsilon} / \mu$ is the unexplained component (residual).

For each explained component, there is elasticity $\beta_{k} \bar{x}_{k} / \mu$ which indicates the impact of each $C I X$ on the total $C I X$ of the dependent variable $y$. We didn't decompose the changes in the CIX of stunting due to insignificant changes in between the two consecutive survey years. If applicable, the total differential decomposition methods (equation 4) of the changes in CIX could be applied to determine the contribution of each factor on the changes in CIX over years. This approach allows determining the impacts of the changes in the regression coefficients, the changes in the mean of the determinants of stunting, and the changes in the degree of inequality in the determinants of stunting.

$\begin{array}{rlr}C I X & =\underset{\mu}{2} \operatorname{cov}(h, r) & \text { Equation (1) } \\ y & =\propto+\sum_{k} \beta_{k} x_{k}+\varepsilon & \\ C I X & =\sum\left(\beta_{k} \bar{x}_{k} / \mu\right) C I X_{k}+G C_{\epsilon} / \mu & \text { Equation (2) } \\ \end{array}$




\section{Statistical methods}

We used STATA version 14 in all analyses. Categorical data were summarized using frequency and percentages while continuous data were summarized using mean and standard deviation. The chi-square test was used to determine if there was a statistically significant difference between proportions. The CIX was computed using the index STATA command. A multivariable Poisson regression model was used to assess the association between stunting and explanatory variables. We used the Poisson regression model instead of the logistic regression model because stunting had prevalence greater than $10 \%$ in each survey year hence termed as being a common outcome.

The complex nature of the survey data was considered by applying the survey (svy) command. The statistical decision criterion was a $5 \%$ level of significance.

\section{Ethical considerations}

Ethical clearance was obtained from the Tumaini University College Research Ethical Committee. Permission to download datasets from DHS measure website was granted. Confidentiality was maintained by not sharing the downloaded dataset with other researchers.

\section{Results}

\section{Description of participant characteristics}

Children were born to 4990, 4,717, and 6,273 mothers for the TDHS 2004/5, 2010, and 2015 respectively. During TDHS 2004/5; the majority were males $3385(50 \%)$, born to mothers with primary education $1872(26.1 \%)$, lived in rural areas 5621 (81\%), and lived in the poorest wealth quintile households 1504 (22.8\%). During TDHS 2010; the majority were males 3203 (49.7\%), born to mothers with primary education 4051 (68.2\%), lived in rural areas 5255 (80.5\%), and lived in poorer wealth quintile households 1462 (23.8\%). During TDHS 2015/6; the majority were males 4230 (50.6\%), born to mothers with primary education 5068 (64.5\%), lived in rural areas 6540 (74.2\%), and lived in the poorest wealth quintile households 1931 (24.4\%).

The mean child age was 29.7 (16.4), 29.2 (16.4), and 29.2 (16.4) months in the years 2004, 2010, and 2016 respectively. The average household size was 7 (4.2), 7.2 (3.8), 7.4 (4.2) for survey years 2004/5, 2010, and 2015/6 respectively. The overall mean HAZ was -180.213 (134.4), -168.6 (140.8), -149.6 (135.2) in the years 2004,2010 , and $2015 / 6$ respectively. (Table 1 ).

\section{Trends of child stunting by socioeconomic status}

Over the years, stunting declined from $45.5 \%$ in 2004 to 42.8 in 2010 and then to $35.6 \%$ in 2016 . The prevalence of stunting significantly declined from $45.5 \%$ to $42.8 \%$ at $p<0.001$ ) for $2004 / 5$ to 2010 respectively and then from $42.8 \%$ to $35.6 \%$ at $p<0.001$ for 2010 and $2015 / 6$ respectively. The overall decline from 2004/5 to 2015/6 was also statistically significant at $p<0.001$ (all p-values computed according to Chi-square test for trend). Basing on socioeconomic status as measured by household wealth index, the larger decline was among the richer wealth quintile households while a small decline was among the richest wealth index. (Table 2).

\section{Trends of socioeconomic inequalities in stunting}

Over the years, the levels of socioeconomic inequalities in stunting were significantly concentrated among the poor as the CIX had negative values in all surveys. The CIX was -0.019 ( $p<0.001), 0.0178(p<0.001)$ and $-0.0096(p<0.001)$ in 2004, 2010 and 2016 respectively. Socioeconomic inequalities in stunting insignificantly declined, the difference in CIX was 0.0015 ( $p=0.7658$ ) from 2004 to 2010 and 0.0081 ( $p=0.1145)$ from 2010 to 2015. (Table 3).

Table 1: Percentage distribution of stunting among under-five children for TDHS 2004/5, 2010 and 2015/6 


\begin{tabular}{|c|c|c|c|}
\hline Characteristics & $2004 / 5(\mathrm{~N}=6,761) \quad n(\%)$ & $2010(N=6415) \quad n(\%)$ & $2015 / 6(N=8,443) n(\%)$ \\
\hline Area of residence & & & $1903(25.8)$ \\
\hline Urban & 1159 (19) & 1177 (19.5) & \\
\hline Rural & $5621(81)$ & 5255 (80.5) & $6540(74.2)$ \\
\hline Maternal education & & & $1855(21.6)$ \\
\hline No education & $1872(26.1)$ & 1645 (25.6) & \\
\hline Primary & $4337(69.4)$ & 4051 (68.2) & $5068(64.4)$ \\
\hline Secondary & $571(4.5)$ & $736(6.1)$ & $1520(14)$ \\
\hline \multicolumn{4}{|l|}{ Maternal BMI } \\
\hline$<18.5$ & $270(48)$ & $313(50.2)$ & $250(40.3)$ \\
\hline$\geq 18.5$ & $2714(45.2)$ & $2326(42.1)$ & $2694(35.3)$ \\
\hline \multicolumn{4}{|l|}{ Childbirth weight } \\
\hline Small & $400(40.2)$ & $246(51.8)$ & $404(48.9)$ \\
\hline Average & $2026(46.8)$ & $1844(43)$ & $2080(35.4)$ \\
\hline Large & $553(45.4)$ & $439(37.9)$ & $438(29.1)$ \\
\hline Wealth quintiles & & & $1931(24.4)$ \\
\hline Poorest & $1504(22.8)$ & $1326(21.7)$ & \\
\hline Poorer & $1360(20.8)$ & $1462(23.8)$ & $1770(21.8)$ \\
\hline Middle & $1364(21.5)$ & $1378(22.5)$ & $1665(19.5)$ \\
\hline Richer & $1501(20)$ & $1314(18.6)$ & $1736(18.2)$ \\
\hline Richest & $1051(14.9)$ & $952(13.4)$ & $1341(16)$ \\
\hline
\end{tabular}

Table 2: Percentage of stunting among children aged 3 - 59 months by socioeconomic status

\begin{tabular}{|llllll|}
\hline Survey year & \multicolumn{5}{l}{ Wealth quintiles } \\
& Poorest & Poorer & Middle & Richer & Richest \\
\hline TDHS 2004/5 & $792(52.3)$ & $691(50.2)$ & $653(48.8)$ & $625(46)$ & $235(23)$ \\
\hline TDHS 2010 & $651(49.3)$ & $670(46.1)$ & $600(45.5)$ & $485(39.5)$ & $238(26.6)$ \\
\hline Difference (\% point) & -3 & -4.1 & -3.3 & -6.5 & 3.6 \\
\hline TDHS 2010 & $651(49.3)$ & $670(46.1)$ & $600(45.5)$ & $485(39.5)$ & $238(26.6)$ \\
\hline TDHS 2015/6 & $777(41.5)$ & $713(40.6)$ & $664(40.2)$ & $506(30.2)$ & $287(20)$ \\
\hline Difference (\% point) & -7.8 & -5.5 & -5.3 & -9.3 & -6.6 \\
\hline TDHS 2004/5 & $792(52.3)$ & $691(50.2)$ & $653(48.8)$ & $625(46)$ & $235(23)$ \\
\hline TDHS 2015/6 & $777(41.5)$ & $713(40.6)$ & $664(40.2)$ & $506(30.2)$ & $287(20)$ \\
\hline Difference (\% point) & -10.8 & -9.6 & -8.6 & -15.8 & -3 \\
\hline
\end{tabular}

Table 3: Trend of inequalities in stunting among children aged 3 - 59 months from 2004 to 2016 


\begin{tabular}{|lll|}
\hline Year & CIX & P-value \\
\hline TDHS 2004/5 & -0.0193 & $<0.001$ \\
\hline TDHS 2009/10 & -0.0178 & $<0.001$ \\
\hline Difference & 0.0015 & 0.7658 \\
\hline TDHS 10 & -0.0178 & $<0.001$ \\
\hline TDHS 2015/16 & -0.0096 & 0.0049 \\
\hline Difference & 0.0081 & 0.1145 \\
\hline TDHS 2004/5 & -0.0193 & $<0.001$ \\
\hline TDHS 2015/6 & -0.0096 & 0.0049 \\
\hline Difference & 0.00965 & 0.0538 \\
\hline
\end{tabular}

CIX: Concentration index

\section{Socioeconomic determinants of child stunting}

Table 4 shows the results from the multivariable pooled Poisson regression models for the factors associated with stunting across two survey phases. We found that for phase l; children living in rural areas had $10 \%(\mathrm{APR}=0.9,95 \% \mathrm{Cl}: 0.81,0.99)$ lower prevalence of getting stunted. Children born to mothers who had at least secondary education had $20 \%(A P R=0.8,95 \% \mathrm{Cl}: 0.64,0.9), 30 \%(\mathrm{OR}=0.7,95 \% \mathrm{Cl}: 0.64,0.86)$ lower prevalence of being stunted for phase I and II respectively. The prevalence of getting stunted decreased as the levels of household wealth increased; there were $50 \%$ (APR= $0.595 \% \mathrm{Cl}$ : $0.44,0.6), 40 \%$ $(A P R=0.6(95 \% \mathrm{Cl}: 0.48,0.7)$ and $50 \%(A P R=0.5(95 \% \mathrm{Cl}: 0.43,0.59)$ lower prevalence of getting stunted among children living in the richest wealth index households for phase I, II and III respectively. (Table 4).

\section{Decomposition of inequality in child stunting}

Household wealth index had a larger contribution by increasing inequalities in stunting in all years although the contribution declined from $93 \%$ in $2004 / 5$ to $72 \%$ in $2015 / 6$. Maternal years of schooling was the second contributor by increasing the levels of inequalities in stunting over time, the contribution increased across surveys from $9 \%$ in $2004 / 5$ to $37 \%$ in $2015 / 6$. Area of residence reduced inequalities in stunting in all surveys although the contribution changed over time by increasing then decreasing. The declined trend of the contribution of the household wealth index to the CIX is consistent with the declining inequalities in stunting measured by the CIX. While CIX declined over time, the contribution of mother's years of schooling increased over time. The insignificant decline of the CIX maybe explaining by the competing effect of household wealth and maternal years of schooling. The variables in this model explained inequalities in stunting more than $80 \%$, the contribution of other factors not explained by the model varied over time as depicted by the residual. (Table 5).

\section{Decomposition of change in socioeconomic inequality in child}

We revealed that inequalities in stunting among children aged 3 - 59 months didn't change significantly. Due to the observed insignificant changes of inequalities in stunting, we will not get useful information by decomposing the observed changes in the concentration index (Table 2).

Table 4: The effect of socioeconomic factors on changes in stunting among children aged 3 - 59 months in the TDHS 2004/5, 2010 and 2015/6 


\begin{tabular}{|c|c|c|c|}
\hline Child stunting & Phase I & Phase II & Phase III \\
\hline & $\underline{2004 / 5-2010}$ & $\underline{2010-2015 / 6}$ & $2004 / 5-2015 / 6$ \\
\hline Characteristics & APR $(95 \% \mathrm{Cl})$ & APR $(95 \% \mathrm{Cl})$ & APR $(95 \% \mathrm{Cl})$. \\
\hline Survey year & $0.96(0.9,1.0)$ & $0.8(0.76,0.88) * * *$ & $0.8(0.74,0.86) * \star \star$ \\
\hline \multicolumn{4}{|l|}{ Area of residence } \\
\hline Urban & 1 & 1 & 1 \\
\hline Rural & $0.9(0.8,0.99)$ * & $1.1(0.93,1.21)$ & $0.97(0.87,1.08)$ \\
\hline \multicolumn{4}{|c|}{ Mother's level of education } \\
\hline No education & 1 & 1 & 1 \\
\hline Primary & $0.99(0.92,1.06)$ & $0.9(0.85,0.97)$ ** & $0.99(0.93,1.07)$ \\
\hline Secondary & $0.8(0.64,0.9) * \star$ & $0.7(0.63,0.85) * * \star$ & $0.9(0.77,1.01)$ \\
\hline \multicolumn{4}{|l|}{ Maternal BMI } \\
\hline$<18.5$ & 1 & 1 & 1 \\
\hline$\geq 18.5$ & $0.89(0.82,0.99)$ * & $0.89(0.8,0.97)^{\star}$ & $0.96(0.86,1.1)$ \\
\hline \multicolumn{4}{|l|}{ Childbirth weight } \\
\hline Small & 1 & 1 & 1 \\
\hline Average & $0.85(0.77,0.9)^{\star \star \star}$ & $0.72(0.66,0.79)^{\star \star \star}$ & $0.77(0.7,0.83)^{\star \star \star}$ \\
\hline Large & $0.72(0.66,0.79)^{\star \star \star}$ & $0.62(0.8,1.1)^{\star \star \star}$ & $0.63(0.59,0.69)^{\star \star \star}$ \\
\hline \multicolumn{4}{|l|}{ Wealth quintiles } \\
\hline Poorest & 1 & 1 & 1 \\
\hline Poorer & $0.9(0.85,1)^{*}$ & $0.9(0.83,0.99)^{*}$ & $0.9(0.87,1.01)$ \\
\hline Middle & $0.88(0.81,0.96)^{*}$ & $0.9(0.82,0.98)^{*}$ & $0.9(0.84,0.99)^{*}$ \\
\hline Richer & $0.8(0.76,0.9) * \star \star$ & 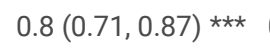 & $0.8(0.74,0.89) * \star \star$ \\
\hline Richest & $0.5(\underline{0.44}, \underline{0.6}) * * *$ & $0.6(\underline{0.48}, \underline{0.7}) * * * \quad 0$ & 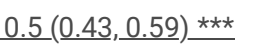 \\
\hline
\end{tabular}

Adjusted for child age, child sex, child-size at birth; diarrhea status, maternal age, zones, cesarean delivery, marital status, skilled birth attendant, number of ANC visits, and year of interview

* Significant at $\mathrm{P}<0.05 ;$ ** Significant at $\mathrm{P}<0.01 ;$ *** Significant at $\mathrm{P}<0.001$

Table 5: Decomposition of concentration indices for under-five stunting in the TDHS 2004/5, 2010 and 2015/6

Stunting (height for age < 2 SD)

TDHS 2004/5 TDHS $2010 \quad$ TDHS 2015/6

$\begin{array}{lllll}\text { Variables } & \text { Contribution } \% & \text { Contribution } & \% & \text { Contribution }\end{array}$ 


\begin{tabular}{|lllllll|}
\hline Residence area & -0.0004 & -2.17 & -0.0004 & -23.8 & 0.001 & -13.65 \\
\hline Child age in (months) & -0.0006 & 3.06 & -0.0006 & 3.5 & -0.0002 & 2.65 \\
\hline Child age squared & 0.0008 & -4.16 & 0.0008 & -4.5 & 0.0003 & -3.26 \\
\hline Child sex & 0.000 & 0.014 & 0.000 & -0.2 & 0.000 & -0.4 \\
\hline Mother education (years) & -0.0017 & 8.95 & -0.004 & 21.6 & -0.004 & 36.6 \\
\hline Wealth index & -0.018 & 93 & -0.016 & 89.5 & -0.007 & 71.5 \\
\hline Household size & 0.0004 & -2.19 & 0 & -0.08 & 0.0005 & -5.4 \\
\hline Skilled birth attendant & -0.004 & 22.58 & 0 & -0.25 & -0.002 & 17.5 \\
\hline Place of delivery & 0.0006 & -3.4 & -0.004 & 23.1 & -0.0016 & 16.2 \\
Residuals & -0.0531 & -15.684 & -0.0518 & -8.87 & -0.063 & -21.74 \\
Total & -0.0229 & 100.00 & -0.0242 & 100.00 & -0.013 & 100.00 \\
\hline
\end{tabular}

Where \%; represents the percentage contribution of the determinant's CIX to the overall CIX

\section{Discussion}

This study aimed to determine the trend, contributing factors, and changes of inequalities in stunting among children aged 3 - 59 months from $2004 / 5$ to 2015/16. Over the years, both stunting and socioeconomic inequalities in stunting declined although burdening among the poor. Socioeconomic inequalities in stunting were mostly accounted for by the differentials in wealth index although the contribution declined over time. This was followed by the differentials in maternal years of schooling whose contribution increased over time. The differences in rural and urban areas reduced socioeconomic inequalities in stunting, the contribution declined over time.

The insignificant decline in socioeconomic inequalities in stunting may be attributed by the role of Tanzania Social Action Fund (TASAF) which empowered communities in accessing, requesting and implementing projects towards improved livelihoods of the poor (31); Big Results Now (BRN) enhanced availability of health services at ward levels for example dispensaries, availability of primary and secondary schools at ward levels $(9,31,32)$ which increased school enrollment. Other scholars found an increasing trend of socioeconomic inequalities in stunting $(5,27,33)$. This may be accounted for by the methodological differences in estimating the levels of inequalities in stunting namely generalized CIX while other researchers used the Wagstaff (34) or Erreygers (35) CIX. Furthermore, we did not involve children below three months. Increased efforts by the government and other stakeholders in strengthening economic empowerment may be through entrepreneurship skills and education on child care practices among women of reproductive age is needed.

Most of the determinants except the area of residence had a positive contribution to socioeconomic inequalities in stunting. This is explained by the higher risk of stunting among the disadvantaged socioeconomic groups who were majority thus the combined marginal effect of each determinant influenced socioeconomic status. The larger contribution of the disparities in household wealth index on the socioeconomic inequalities in stunting may be explained by the majority of stunted children living in poor and poorest wealth indexes. Similar results by $(22,23)$ implying that equal distribution of stunting will be maintained if efforts are embarked on equal distribution of socio services like roads, water, and hospitals which will easy transportation of raw materials for construction of households, availability of safe water at the household level and health monitoring respectively.

The increased contribution of differentials in maternal years of schooling on the socioeconomic inequalities in stunting may be explained by a larger number of mothers with lower levels of education who have a small number of years in schools and had a large number of stunted children. Women from economically disadvantaged households are either not getting more opportunities to achieve better education or after being enrolled they drop out. These findings were consistent with $(22,23)$. These findings may imply a strengthening of education among mothers of childbearing age principally through continued programs under Big Results Now (BRN) programs, increase school enrollment of female children as well as mass media exposure and nutrition campaign.

The declined contribution of differentials in area of residence on the socioeconomic inequalities in stunting may be explained by governmental efforts of distributing socioeconomic infrastructures in both rural and urban areas which bridges up the gap. These results were consistent with other scholars (26,36), although the area of residence may be interlinked with other socioeconomic factors including wealth and level of education (25). We saw that the effect of area of residence on stunting was confounded by wealth index, similar observations may be on the contribution of the area of residence to socioeconomic inequalities in stunting.

We didn't decompose the changes in concentration indexes to get the factors for the changes in inequalities in stunting as there were no significant changes in CIXs between two surveys. We did not access scholars who found insignificant changes in inequalities in stunting, although our findings can be compared to (5) who found insignificant changes in inequalities in wasting when decomposing the changes in inequalities in malnutrition and hence didn't decompose the CIX for wasting. Insignificant changes in inequalities in stunting means that significant disparities in stunting didn't significantly increase. A big lesson is that, as we have identified the determinants of unequal distribution of stunting in each survey year, tackling these determinants may bring a significant decrease in the unequal distribution of stunting which is the required step towards attaining zero stunting and under-nutrition as a whole. 
This paper contributes to the existing literature on different aspects. Firstly, we provide country estimates of the current levels of stunting among children aged 3 - 59 months where stunting is accurately captured rather than involving even children aged below 3 months. Although the minor difference in the proportions of stunted children was observed as compared to (13) for the survey year 2015/6. Secondly, we assessed how socioeconomic inequalities in stunting evolve, thus this is the first study to examine the trend in socioeconomic inequalities in stunting to Tanzania using the most three recent DHS. Thirdly, had a larger sample size which gives enough power to make conclusions on the socioeconomic determinants of inequalities in stunting across years. Last but not least we put more emphasis on optimal health growth, as we evaluated child health equity using Wagstaff and Watanabe decomposition methods of the CIX.

Despite the drawn conclusions basing on our study findings, these results should be interpreted with caution as we faced several limitations. Firstly, inadequate information collected from the respondent for-instance lack of information on religion and maternal feeding practices and dietary diversity gives the room of worrying about confounding effects as these variables were not included in the model. Secondly, children not living with their mothers were not included in this study ever since we aimed to evaluate the effect of maternal characteristics on child growth thus including children not living with their mothers could lead to biased estimates. Fourthly, the use of wealth index for comparison purposes across DHS as different items were used in the construction of the wealth index in each survey year. Last but not least, we adhered to Wagstaff and Wantanabe decomposition methods which are limited to continuous variables or dichotomous variables.

\section{Conclusion}

To attain a significant reduction of stunting among the disadvantaged groups and hence zero stunting by 2030, policies should encompass economic empowering of the socio-disadvantaged group for-instance; through housing, employment, and income. Secondly, the continued provision of free education specifically among the socio-disadvantaged groups thereby capacitating graduates through employment is very vital. Thirdly, further researches should incorporate maternal feeding practices and food taboos as they affect fetal growth during pregnancy. Last but not least, studies on socioeconomic inequalities in wasting and underweight are vital as they are interlinked with stunting.

\section{List Of Abbreviations}

ANC - Antenatal care; BRN - Big Results Now; BMI - Body Mass Index; CIX - Concentration index; DHS - Demographic and Health Surveys; HAZ - Height for Age Z- scores; MDGs - Millennium Development Goals; SDGs - Sustainable Development Goals; svy - Survey TDHS - Tanzania Demographic and Health Surveys; TASAF - Tanzania Social Action Fund

\section{Declarations}

\section{Ethics approval and consent to participate}

Not applicable as we used secondary data from DHS.

\section{Consent for publication}

Not applicable

\section{Availability of data and materials}

The datasets were downloaded from DHS measure website at http://dhsprogram.com/data/available-datasets.cfm

\section{Competing interests}

No competing interest declared

\section{Funding}

This work was supported through the DELTAS Africa Initiative Grant No. 107754/z/15/zDELTAS Africa SSACAB. DELTAS Africa is an independent funding scheme of the African Academy of Sciences (AAS)'s Alliance for Accelerating Excellence in Science in Africa (AESA) and supported by the New Partnership for Africa's Development Planning and Coordinating Agency (NEPAD Agency) with funding from the Wellcome Trust (Grant No.107754/Z/15/Z) and the UK government. The views expressed in this publication are those of the author(s) and not necessarily those of AAS, NEPAD Agency, Wellcome Trust, or the UK government. The funding was for pursuing a Master degree in Epidemiology and Applied Biostatistics, of which the research component was embedded. Upon completion of studies, the main author was fully funded by SSACAB to attend the Biostatistics International Conference (SUSAN - SSACAB - 2019 Conference) in Cape Town - South Africa where the results of this paper were presented.

\section{Author's contribution}

EM* designed and conceptualized the study, conducted all data analysis and report writing, and hence the production of this paper. MJM and SEM supported during study conceptualization and presentations, RP and MM helped in conceptualizing the study, proposal writing, and the production of the research report. FC and EM guided the formulation of the research gap. All authors read and approved the final manuscript.

\section{Acknowledgment}


Hereby acknowledging my employer the College of Business Education for granting me the study leave, the Kilimanjaro Christian Medical University College is the training institution of study and the Demographic Health Surveys Measure for giving access to use the data. More importantly, the DELTAS SSACAB for funding my studies.

\section{Author's details}

${ }^{1}$ Department of Epidemiology and Biostatistics, Institute of Public Health, Kilimanjaro Christian Medical University College, P.O. Box 2240, Moshi, Tanzania. ${ }^{2}$ Department of Mathematics and Statistics, College of Business Education, P.O. Box 1968, Dar es Salaam Tanzania. ${ }^{3}$ Department of Business Administration, College of Business Education, P.O. Box 1968, Dar es Salaam, Tanzania. ${ }^{4}$ Data unit, Ifakara Health Institute (IHI), P.O. Box 78373 Tanzania.

\section{References}

1. Unicef. Levels and Trends in Child Malnutrition: UNICEF / WHO / World Bank Group Joint Child Malnutrition Estimates. Vol. 12, Midwifery. 2018.

2. Hoddinott J, Alderman H, Behrman JR, Haddad L, Horton S. The economic rationale for investing in stunting reduction. Matern Child Nutr. 2013;9(S2):69-82.

3. Olofin I, McDonald CM, Ezzati M, Flaxman S, Black RE, Fawzi WW, et al. Associations of Suboptimal Growth with All-Cause and Cause-Specific Mortality in Children under Five Years: A Pooled Analysis of Ten Prospective Studies. PLoS One. 2013;8(5).

4. Deborah A, Kavita S, Elisabeth S, Lesley O, Tara K, Joyceline K, et al. Reducing Malnutrition in Tanzania:Estimates to Support Nutrition Advocacy: Tanzania PROFILES 2014. Available from: https://www.fantaproject.org/sites/default/files/resources/Tanzania-PROFILES-Report-2014-June2017.pdf

5. Kien VD, Lee H-Y, Nam Y-S, Oh J, Giang KB, Minh H Van. Trends in socioeconomic inequalities in child malnutrition in Vietnam: findings from the Multiple Indicator Cluster Surveys, 2000-2011 Vu. 2016;9716.

6. Hangoma P, Aakvik A, Robberstad B. Explaining changes in child health inequality in the run up to the 2015 millennium development goals (MDGs): The case of Zambia. PLoS One. 2017;12(2):1-21.

7. Kröger H, Pakpahan E, Hoffmann R. What causes health inequality? A systematic review on the relative importance of social causation and health selection. Eur J Public Health. 2015;25(6):951-60.

8. Crochemore I, Silva M da, França G V, Barros AJ, Amouzou A, Krasevec J, et al. Socioeconomic inequalities persist despite declining stunting prevalence in low- and middle-income countries. J Nutr. 2018;148(2):254-8.

9. MoHCDGEC, NBS, ICF. Demographic and Health Survey and Malaria Indicator Survey 2015-16. 2016.

10. IRS. Overcoming the Challenges of Under-Nutrition in Tanzania Through 2021: Reflecting on Trends, Questions, and Future Scenarios for Urgent Nutrition Action. 2017. Available from: https://www.actionagainsthunger.org.uk/publication/overcoming-challenges-undernutrition-tanzania-through2021

11. Mgongo M, Chotta NAS, Hashim TH, Uriyo JG, Damian DJ, Stray-pedersen B, et al. Underweight, Stunting and Wasting among Children in Kilimanjaro Region , Tanzania; a Population-Based Cross-Sectional Study. 2017;1-12.

12. United Republic of Tanzania. Tanzania National Nutrition Survey 2018. 2019. 144 p.

13. Chirande L, Charwe D, Mbwana H, Victor R, Kimboka S, Issaka Al, et al. Determinants of stunting and severe stunting among under-fives in Tanzania: Evidence from the 2010 cross-sectional household survey. BMC Pediatr. 2015;15(1):1-13. Available from: http://dx.doi.org/10.1186/s12887-015-04829

14. Khamis AG, Mwanri AW, Ntwenya JE, Kreppel K. The influence of dietary diversity on the nutritional status of children between 6 and 23 months of age in Tanzania. BMC Pediatr. 2019;19(1):1-9.

15. Rutstein SO, Rojas G. Guide to DHS statistics [Internet]. Calverton, MD: ORC Macro. 2006. Available from: http://www.measuredhs.com/pubs/pdf/DHSG1/Guide_to_DHS_Statistics_290ct2012_DHSG1.pdf\%5Cnhttp://citeseerx.ist.psu.edu/viewdoc/download? doi=10.1.1.431.8235\&rep=rep1\&type=pdf

16. De Onis M, Blössner M. WHO Global Database on Child Growth and Malnutrition. Programme of Nutrition World Health Organization Geneva. 1997.

17. Rutstein SO, Johnson K. DHS Comparative Reports No.6: The DHS Wealth Index. MEASURE DHS. 2018.

18. Rutstein SO, Rojas G. Guide to DHS Statistics. Demographic and Health Surveys Methodology. DHS Publication. 2006. Available from: http://www.measuredhs.com/pubs/pdf/DHSG1/Guide_to_DHS_Statistics_290ct2012_DHSG1.pdf

19. Ruel MT, Alderman H. Nutrition-sensitive interventions and programmes: How can they help to accelerate progress in improving maternal and child nutrition? Lancet. 2013;382(9891):536-51. Available from: http://dx.doi.org/10.1016/S0140-6736(13)60843-0

20. Bhutta ZA, Das JK, Rizvi A, Gaffey MF, Walker N, Horton S, et al. Evidence-based interventions for improvement of maternal and child nutrition: What can be done and at what cost? Lancet. 2013;382(9890):452-77.

21. Chirande L, Charwe D, Mbwana H, Victor R, Kimboka S, Issaka Al, et al. Determinants of stunting and severe stunting among under-fives in Tanzania: evidence from the 2010 cross-sectional household survey. BMC Pediatr. 2015;1-13. Available from: http://dx.doi.org/10.1186/s12887-015-0482-9

22. Poel E Van De, Speybroeck N. Decomposing malnutrition inequalities between Scheduled Castes and Tribes and the remaining Indian population. Ethn Health. 2010;(October 2014):37-41.

23. Rabbani A, Khan A, Yusuf S, Adams A. Trends and determinants of inequities in childhood stunting in Bangladesh from 1996 / 7 to 2014 . Int J Equity Health. 2016;1-14. Available from: http://dx.doi.org/10.1186/s12939-016-0477-7

Page $10 / 11$ 
24. Modern G, Sauli E, Mpolya E. Correlates of diarrhea and stunting among under-five children in Ruvuma, Tanzania; a hospital-based cross-sectional study. Sci African. 2020;8:e00430. Available from: https://doi.org/10.1016/j.sciaf.2020.e00430

25. Paraje G. Child stunting and socio-economic inequality. Cepal Rev. 2009;99:1-26.

26. Zere E, McIntyre D. Inequities in under-five child malnutrition in South Africa. Int J Equity Health. 2003;2:1-10.

27. Akombi BJ, Agho KE, Renzaho AM, Hall JJ, Merom DR. Trends in socioeconomic inequalities in child undernutrition: Evidence from Nigeria demographic and health survey (2003 - 2013). PLoS One. 2019;14(2):1-13.

28. Donnell OO, Wagstaff A, Lindelow M. Analyzing Health Equity Using Household Survey Data. Washington, D.C.: The World Bank; 2008. Available from: www.worldbank.org

29. Kakwani N, Wagstaff A, Doorslaeff E Van. Socioeconomic inequalities in health: Measurement , computation , and statistical inference. $1997 ; 77$.

30. Kakwani N, Wagstaff A, van Doorslaer E. Socioeconomic inequalities in health: Measurement, computation, and statistical inference. Vol. 77, Journal of Econometrics. 1997.

31. TASAF. Tanzania Second Social Action Fund: First Quarter Implementation Progress Report (July - September 2011). 2011. Available from: www.tasaf.org:

32. Ministry of Health. The National Road Map Strategic Plan to Improve Reproductive, Maternal, Newborn, Child and Adolescent Health in Tanzania - One Plan II. 2016;(June):142.

33. Salvucci V. Determinants and Trends of socioeconomic inequality in child malnutrition: The case of Mozambique, 1996-2011. Annu Conf Hum Dev Capab Assoc New Delhi. 2008;168(10-13):1-30.

34. Wagstaff A, Watanabe N. Socioeconomic Inequalities in Child Malnutrition in the Developing World. The Development Dilemma. 2000.

35. Erreygers G. Beyond the Health Concentration Index: An Atkinson Alternative for the Measurement of the Socioeconomic Inequality of Health. Vol. 37, Biological Research. 2005.

36. Angdembe MR, Dulal BP, Bhattarai K, Karn S. Increased risk of low birthweight and preterm birth, stunting in infancy, short adult height, poor schooling, and higher adult fasting glucose concentrations. The. Int J Equity Health. 2019;18(42):1-17. Available from: https://doi.org/10.1186/s12939-019-0944Z 